\title{
DEVELOPMENT OF NUMERICAL MODEL FOR THE DESIGN OF LOW-NOISE BALLASTED TRACK
}

\author{
JUNYANG ZHANG ${ }^{1}$, BERNHARD LECHNER ${ }^{1}$, STEPHEN FREUDENSTEIN ${ }^{1}$, JEAN-MARC WUNDERLI ${ }^{2}$, \\ ARMIN ZEMP ${ }^{2}$, GWENAEL HANNEMA² \& MARKUS HECHT ${ }^{3}$ \\ ${ }^{1}$ Technical University Munich, Germany \\ ${ }^{2}$ Empa Switzerland, Switzerland \\ ${ }^{3}$ Technical University Berlin, Germany
}

\begin{abstract}
Noise is a significant environmental problem in railway transportation systems. The rail transport policy of the EU and Switzerland is asking for efficient, innovative track systems, which are able to reduce rail noise. A project named OST funded by BAFU Switzerland was carried out under the co-operation with Empa (Switzerland), Technical University of Munich and Technical University of Berlin, had the target to develop a numerical model to predict the noise and vibration of ballasted track caused by passing trains. A co-simulation chain for transient acoustic simulation between multi body simulation (for structure-borne vibration) and finite element simulation (for sound radiation and for air-borne sound propagation) was established and the interface was developed. The numerical model was validated through laboratory tests on the test track of Technical University of Munich and field measurements on the track section Rothenthurm in Switzerland. The model aims to predict the acoustic effect of different railway superstructure components such as different sleeper types, rail profiles and rail pad stiffness.

Keywords: 3D-modelling, air-borne noise propagation, co-simulation, finite element method, low-noise ballasted track, modal analysis, multibody simulation, rail-wheel contact, structure-borne vibration, vehicle-track interaction.
\end{abstract}

\section{INTRODUCTION}

The general method to treat the railway noise problem, which is based on the measurement to determine the acoustic vibration properties of the components, costs a lot for setting up the equipment only in a single measurement section. Therefore, there is a demand to develop a numerical model to investigate new designs of the superstructure to optimize the acoustic vibration behaviour. Under the cooperation of Technical University of Munich, research institute Empa (Switzerland) and Technical University of Berlin a numerical model for ballasted track system was developed. The whole project, named OST (Zhang et.al. [3]) was funded by the BAFU (Switzerland). The model was validated through field measurement on the track section in Rothenthurm in Switzerland and laboratory tests on the test track at the Technical University of Munich. In order to minimize the noise, the consideration of the whole system under track/vehicle interaction is necessary. The FEM (finite element method) and MBS (multibody simulation) co-simulation method realizes the calculation of important superstructure acoustic vibration such as rails and sleepers under the consideration of track/ vehicle coupled dynamic effects. The essential parameters lead to wheel/rail contact excitations such as wheel/rail roughness. Track irregularities can be measured from the real track section and used as input in the numerical model. The different materials and design geometries of the superstructure components can be varied in the model. The model can calculate the system response under different stiffness and damping values of force elements to simulate the effect of different rail pad types and ballast support conditions in reality. This paper explains the numerical modelling workflow (Freudenstein et al. [1], Hecht et. al. [2]) using 
the full 3D components and the corresponding validation process. On the one side, it offers the functionalities to investigate the effect of component geometry designs such as different kinds of sleepers and rail profiles on the vibratory response. On the other side, it is available to calculate the surface normal velocities of the components in the three-dimensional space in order to give a precise output to calculate the sound propagation and to compare with the microphone measured data. The modelling process and corresponding validations were divided into two major steps. The first step is to create a model to simulate the properties and the test scenarios on the test track of the Technical University of Munich (named as Munich test track). The target of the tests on the Munich test track is to investigate the response of the ballasted track under certain frequency excitation in order to give a basic understanding of the vibration mechanism without the complex excitation from the wheel/rail contact. The second step is to create a model to reproduce the system response caused by a passing train. The field measurement was carried out in a section at the place of Rothenthurm in Switzerland. The calculated response of the system during the train passing such as displacement, acceleration of the rails and sleepers were validated with the measured data.

\section{MODELLING AND VALIDATION OF MUNICH TEST TRACK MODEL}

\subsection{General Information about the Munich Test Track Model}

The Munich test track is $12 \mathrm{~m}$ long, the rail profile is $60 \mathrm{E} 2$ and there are $18 \mathrm{~B} 70$ sleepers in the test track. The rail pad type is $\mathrm{Zw} 700$. The measurements on the test track were focused on the determination of natural frequencies and the validation of the numerical model in the time domain to investigate the damping effects. Figure 1 shows an overview of the Munich test track and the test equipment. Firstly, a sweep excitation from 40 to $8,000 \mathrm{~Hz}$ using a shaker was applied on the rail in the vertical and lateral direction. The scanning laser Doppler

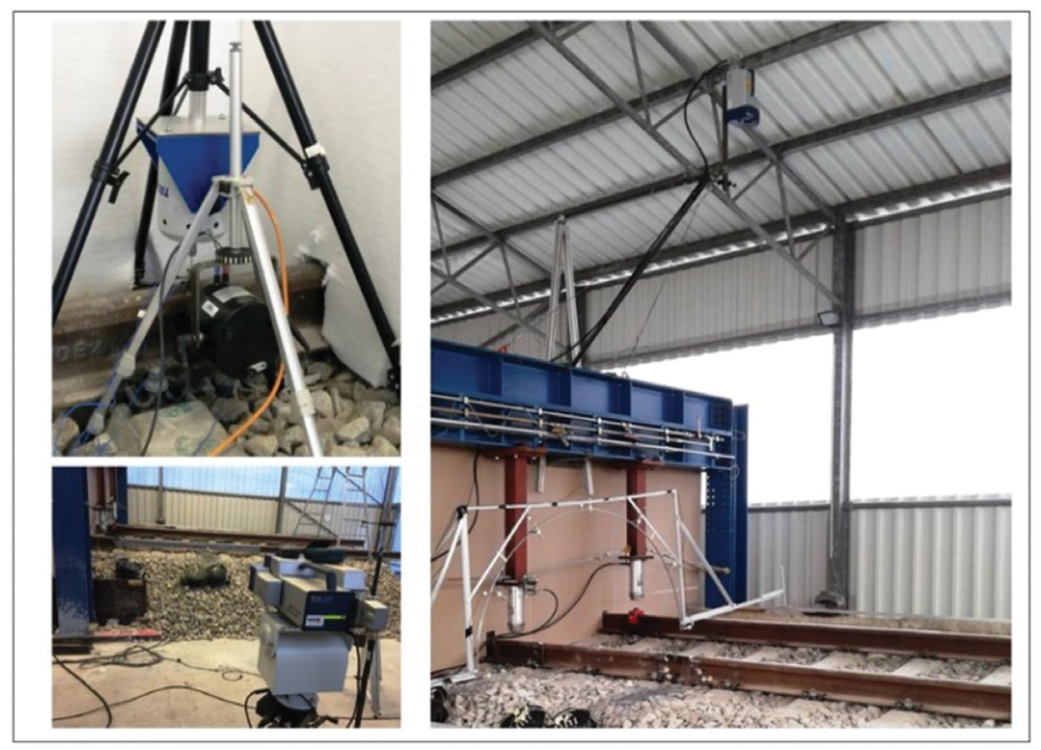

Figure 1: Overview of the Munich test track and measurement devices. 
vibrometer detects the system natural frequencies. Secondly, sine wave excitations with selected system natural frequencies were applied on the rail and sleeper of the test track in order to determine the vibration amplitude. This is one of the most important parameters for validation of the system damping behaviour in the numerical model.

\subsection{Modelling of Munich Test Track Model}

Figure 2 shows the Munich test track model. This model was assembled with components such as sleepers and rails in MBS (Multi-Body-Simulation) Software SIMPACK environment. The rails and sleepers are flexible bodies. The fastening systems such as tension clips and rail pads were modelled as coupled force elements. The ballast, which supports the sleepers was also created as a set of force elements in the model. The 3D bodies of rails and sleepers were created according to the technical drawings in software AutoCAD to ensure geometric precision. After that, the 3D components were used for the FE-Analysis. A process called "modal reduction" for preparing the input to MBS environment was done in the FE model.

Modelling and validation of rail 60E2: Fig. 3 shows the modelling and validation workflow of creation rail $60 \mathrm{E} 2$ model.

The $1.5 \mathrm{~m}$ long rail section of the $60 \mathrm{E} 2$ profile is based on the standard drawing of DIN EN 13674-1 created as a 3D model in AutoCAD. The modal analysis is performed in FESoftware environment ANSYS, then the model is imported into MBS Software environment SIMPACK. The experimental modal analysis was carried out through the impulse test on three $1.5 \mathrm{~m}$ rail samples of the same rail section in order to validate the model. According to the test experience, elastic pads were used to support the test rail sections in order to get a clear response result.

Table 1 collects the natural frequencies from simulation and measurement. It can be seen that the values calculated from the 3D rail model match the test results very well. The modal analysis provides the most important dynamic properties, which proves the correctness of the created 3D model. It also shows that this modelling method can provide a base for building new standard models for dynamic analysis. Now one can change the parameters to create other rail profiles or any length of the rail section without the requirement for further

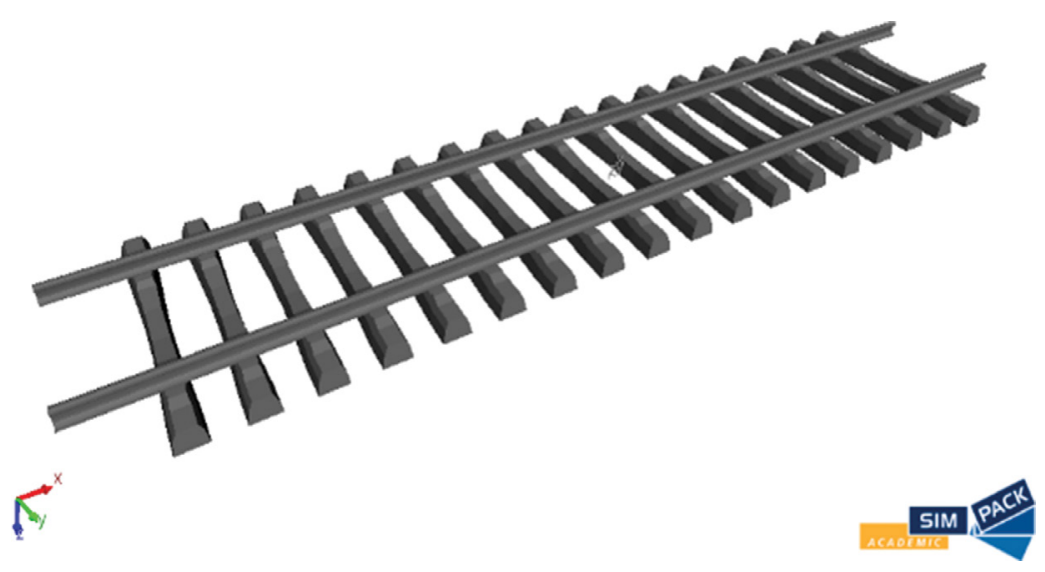

Figure 2: Munich test track model. 


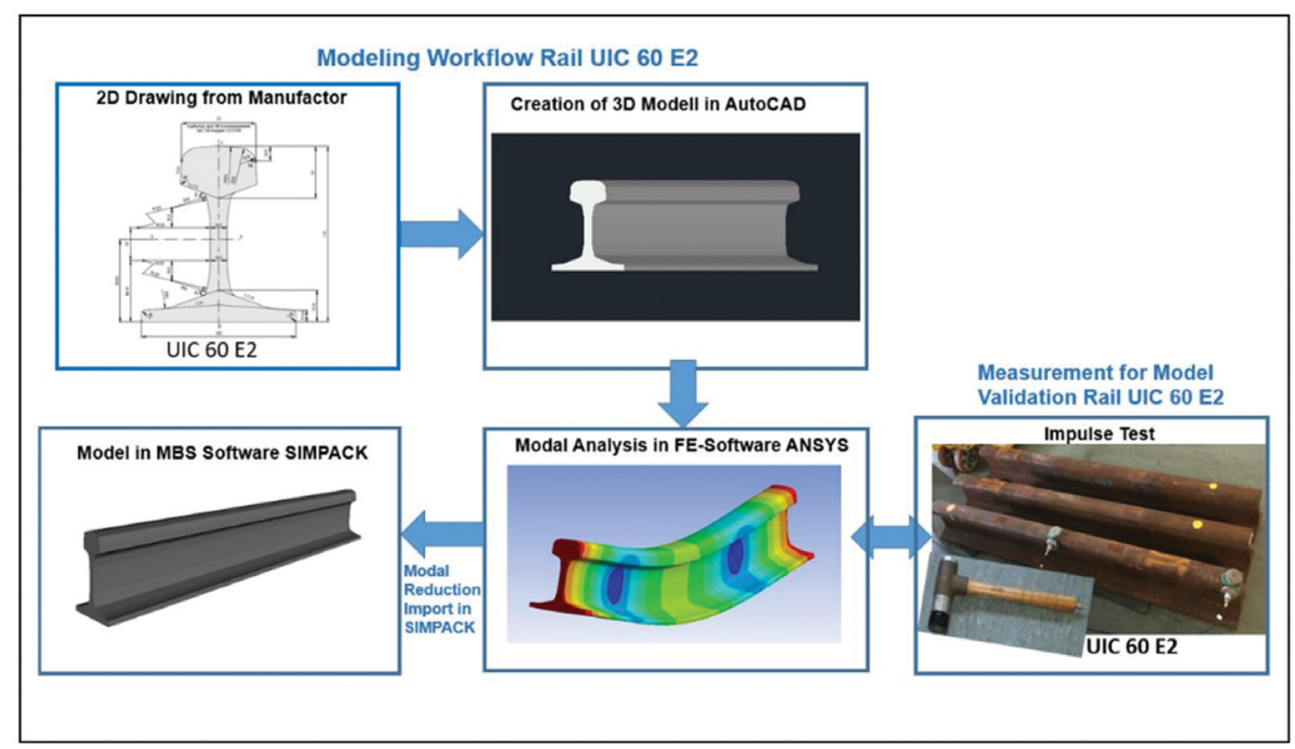

Figure 3: Workflow of modelling and validation of rail 60E2.

Table 1: Rail natural frequencies of FE-model (ANSYS) and measurement.

\begin{tabular}{lllll}
\hline \multirow{2}{*}{ Mode } & \multicolumn{4}{c}{ Natural frequencies (Hz) rail 60 E2 $1.5 \mathrm{~m}$} \\
\cline { 2 - 5 } & $\begin{array}{l}\text { Vertical } \\
\text { (ANSYS) }\end{array}$ & $\begin{array}{l}\text { Vertical } \\
\text { measurement }\end{array}$ & $\begin{array}{l}\text { Lateral } \\
\text { (ANSYS) }\end{array}$ & $\begin{array}{l}\text { Lateral } \\
\text { measurement }\end{array}$ \\
\hline 1 & 455 & 462 & 199 & 202 \\
2 & 1,065 & 1,085 & 506 & 511 \\
3 & 1,756 & 1,787 & 893 & 894 \\
4 & 2,441 & 2,484 & 1,343 & 1,367 \\
\hline
\end{tabular}

measurements to validate the models. The rail section of length $1.5 \mathrm{~m}$ was extruded to 12 $\mathrm{m}$ and it was used as the rail component for the Munich test track model. A model database including various types of rail profiles for further investigations was created using the same modelling workflow.

Modelling and validation of B 70 sleeper model: Fig. 4 shows the modelling and validation workflow of B 70 sleeper. The pre-stressing rebar and the connection condition between the rebar and the sleeper concrete were defined in ANSYS Workbench. The sleeper model with pre-stressing wires has 1 st bending frequency at about $10 \mathrm{~Hz}$ higher than the model without wires. The pre-stressing force effect was treated indirectly by increasing the elastic modulus property of the sleeper material in the model. Since the geometry of the sleeper is complex and also meshing quality influence the calculation time and accuracy, a high meshing quality with ICEM-Module in ANSYS was required. Finally, the FE-model was imported into MBS 




Figure 4: Workflow of modelling and validation of B 70 sleeper.

Software environment SIMPACK through the modal reduction process and used as sleeper component in the Munich test track model. To validate the model, the weight of three B 70 sleepers was checked. The measured average value is very similar to the calculated value. For further validation, the hammer impact test was carried out. Since the support conditions have great influence on the response, several support conditions were tested.

Table 2 collects the natural frequencies from simulation and measurement under different contact conditions. It is evident that the values calculated from the $3 \mathrm{D}$ sleeper model are consistent with the measured data with elastic pad supports.

Support stiffness and damping of the Munich test track model: The support conditions of the system (supports for sleepers and rails) were created as coupled force elements in the SIMPACK software environment. The support values of stiffness and damping used in the model are summarized in Table 3.

Calculated and measured results: The dynamic investigations to determine the natural frequencies of the experimental track were carried out by Empa, Laboratory for Acoustics/Noise Control. The dynamic excitations were realized by sweep excitation by a shaker mounted on the rail. The sweep excitation frequencies ranged from $40 \mathrm{~Hz}$ to $8,000 \mathrm{~Hz}$, both in the vertical and in the lateral excitation direction. The system responses, in particular the relevant resonant frequencies, were determined separately for the vertical and lateral directions by scanning laser Doppler vibrometer. Table 4 summarizes all the decisive track natural frequencies of numerical model and measurements. It can be concluded that the calculated natural frequencies meet the measured natural frequencies.

The system response amplitude is also an essential parameter to evaluate the structural dynamics of the system natural frequencies. The sine wave excitations under selected natural frequencies were applied on the rails and sleepers. The installed acceleration sensors determine the oscillations of rails and sleepers. This measured response amplitude was used to validate the calculated results. 
Table 2: Sleeper natural frequencies of FE analysis and measurement.

\begin{tabular}{|c|c|c|c|c|}
\hline \multirow[t]{2}{*}{ Mode } & \multicolumn{4}{|c|}{ Vertical natural frequencies (Hz) B 70 sleeper } \\
\hline & $\begin{array}{l}\text { FE } \\
(\mathrm{ANSYS})\end{array}$ & $\begin{array}{l}\text { Experimental } \\
\text { support: elastic pads }\end{array}$ & $\begin{array}{l}\text { Experimental } \\
\text { support: wood block }\end{array}$ & $\begin{array}{l}\text { Experimental } \\
\text { support: hanging }\end{array}$ \\
\hline 1 & 118 & 118 & 136 & 115 \\
\hline 2 & 352 & 352 & 360 & 352 \\
\hline 3 & 673 & 686 & 688 & 685 \\
\hline 4 & 1,057 & 1,078 & 1,084 & 1,078 \\
\hline
\end{tabular}

Table 3: Support stiffness and damping of the Munich test track model.

\begin{tabular}{ll}
\hline Sleeper vertical support stiffness & $40.8 \mathrm{kN} / \mathrm{mm}$ \\
Sleeper vertical support damping & $5,000 \mathrm{Ns} / \mathrm{m}$ \\
Sleeper lateral support stiffness & $15 \mathrm{kN} / \mathrm{mm}$ \\
Sleeper lateral support damping & $2,500 \mathrm{Ns} / \mathrm{m}$ \\
Rail vertical support stiffness & $23.5 \mathrm{kN} / \mathrm{mm}$ \\
Rail vertical support damping & $5,000 \mathrm{Ns} / \mathrm{m}$ \\
Rail lateral support stiffness & $25 \mathrm{kN} / \mathrm{mm}$ \\
Rail lateral support damping & $2,500 \mathrm{Ns} / \mathrm{m}$ \\
\hline
\end{tabular}

Table 4: Measured and simulated natural frequencies of Munich test track.

\begin{tabular}{lll}
\hline Modes & $\begin{array}{l}\text { Frequency [Hz] } \\
\text { Measurement }\end{array}$ & $\begin{array}{l}\text { Frequency [Hz] } \\
\text { Simulation }\end{array}$ \\
\hline Sleeper rotation centreline & 41 & 42 \\
Vertical full track motion & 51 & 50 \\
Sleeper 1st bending mode & 131 & $129-135$ \\
Sleeper 2nd bending mode & 312 & 312 \\
1st lateral pin-pin bending mode & 494 & $480-542$ \\
Sleeper 3rd bending mode & 685 & 685 \\
1st vertical asymmetric pin-pin bending mode & 998 & 1,000 \\
1st vertical symmetric pin-pin bending mode & 1,052 & 1,084 \\
\hline
\end{tabular}

The numerical model was also created under the same test scenarios of the measurement. Figure 5 shows an example of the Munich test track model to reproduce one of the measurement scenarios and the system response in the vertical direction.

The shaker excitation used in the simulation was exactly the same as the one applied in the experiment. The simulated and measured response at the position of the acceleration sensor Nr.31 under shaker excitation at $491 \mathrm{~Hz}$ was selected as an example to illustrate the results (Fig. 6). 




Figure 5: Munich test track model to reproduce the test scenarios.



Figure 6: Comparison of the excitation and the response of measurement and simulation.

The calculated system response amplitude fits with the measured data in corresponding conditions. However, it was also determined that the tolerance of the system response between the measurement and simulation increases with increasing distance from the shaker, which indicates the decay behaviour in the track longitudinal direction requires further research to validate the numerical model.

Development of transient co-simulation interface between structure vibration and sound radiation: Based on the model of Munich test track, the wheel/rail contact was established on it and a test concept to achieve the transient co-simulation between the structural vibration and the sound radiation under the excitation of rail/wheel contact were developed. Figure 7 displays an overview of the co-simulation concept. 


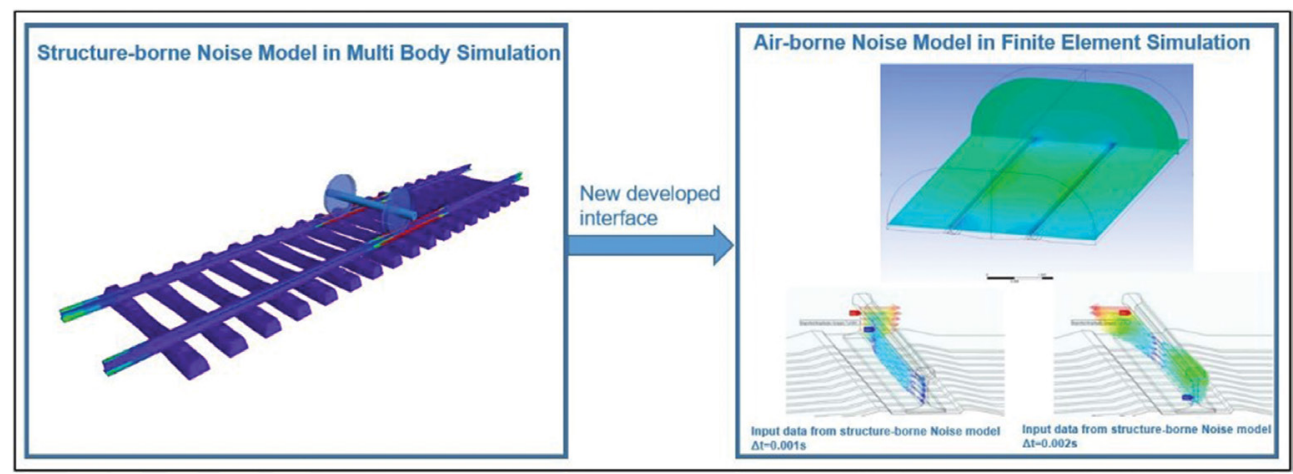

Figure 7: Overview of transient co-simulation between structural vibration and sound propagation.

With the structural vibration model (model in MBS-software SIMPACK environment), calculated node normal surface velocity can be sorted by node ID numbers and the corresponding coordinate system automatically imported into the sound radiation model (model in FE-software ANSYS Acoustic environment) in order to calculate the radiated sound field.

\section{MODELLING AND VALIDATION OF ROTHENTHURM TRACK MODEL}

The second major step of the project was to create the numerical model to predict the system response under the train passing with real rail/wheel contact excitations. To get the input and validation data for the simulation, the field measurements were performed on the track section at Rothenthurm in Switzerland. A measurement locomotive from Prose AG ran several times through the test section. The evaluated data was used to validate the numeric model. The basic parameter information of the track and the measurement locomotive are collected in Table 5.

Fig. 8 shows an example of the field measurement track and the devices. The displacement transducers for determining the sleeper vertical deflection were installed on the measurement base. The deflection of three sleepers during the passing trains was recorded. The displacement transducers for determining the rail deflection in the vertical and lateral direction were installed on the sleepers.

The following measurements were carried out on the track section:

- Track geometry (unloaded);

- Sleeper support conditions;

- Rail surface roughness;

- Rail profile;

- Track decay rate;

- Vertical and lateral rail and sleeper displacement during the train passing;

- Vertical and lateral rail and sleeper accelerations during the train passing;

- Vertical and lateral rail strain during the train passing. 
Table 5: Basic parameters of the measured track section and measurement locomotive.

\begin{tabular}{lc}
\hline Basic parameters of the measured track section \\
\hline Track cant & $0 \mathrm{~mm}$ (straight alignment) \\
Rail & $\mathrm{S} 54$; inclination $1: 40$ \\
Sleeper type & Concrete sleeper B 91 \\
Sleeper spacing & $0.6 \mathrm{~m}$ \\
Fastening system & W 14 with SKL 14 (Clamping force: $18-20 \mathrm{kN}) ;$ \\
& Wfp $14 \mathrm{k}$; Rail pad Zw 686 with $c \approx 450 \mathrm{kN} / \mathrm{mm}$ \\
Ballast thickness & $0.4 \mathrm{~m}$ (standard) \\
\hline Basic parameters of the measurement locomotive \\
\hline Wheel base & $2.6 \mathrm{~m}$ \\
Bogie base & $10.4 \mathrm{~m}$ \\
Wheel load & $10.75 \mathrm{t}$ \\
Passing velocity & $68 \mathrm{~km} / \mathrm{h}$ \\
\hline
\end{tabular}



Figure 8: An example of field measurement track and devices. 


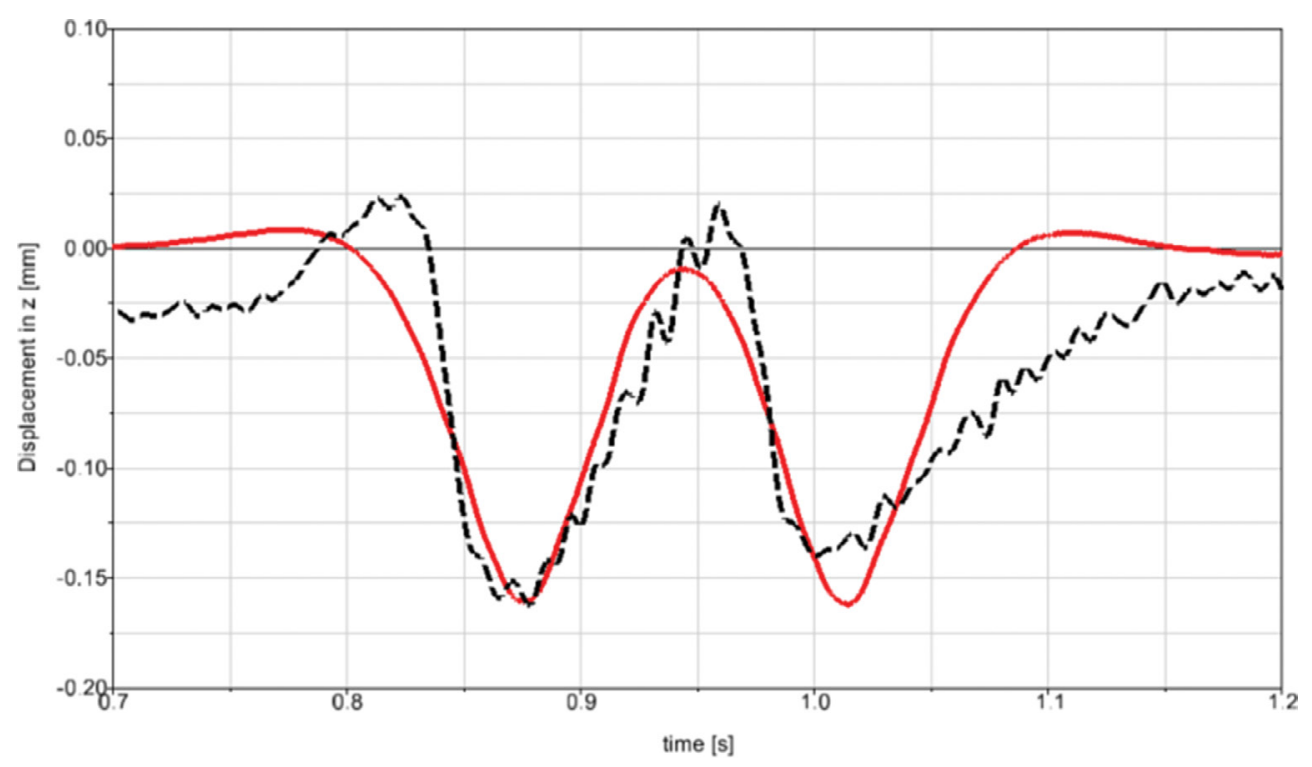

Figure 9: Vertical sleeper displacement of simulation and measurement.



Figure 10: Rail vertical accelerati on of simulation and measurement in the frequency domain.

Figure 9 shows the vertical sleeper displacement. The measured maximum vertical sleeper displacement was used as a target to validate the model. The vertical sleeper support stiffness in the model is $160 \mathrm{kN} / \mathrm{mm}$. The corresponding calculated ballast bedding modulus is $0.235 \mathrm{~N} / \mathrm{mm}^{3}$. The ballast bedding modulus is consistent with the situation of the measured track section [4]. 
The essential validation parameter to check the modelling quality for acoustic or high frequency analysis is the acceleration. Figure 10 shows that the rail acceleration in the numerical model met the measured acceleration very well until 2,000 Hz. A tool to convert the acceleration data to audio data was developed with MATLAB. From the converted audio data one can also confirm, that the relative low frequency range (here until $2,000 \mathrm{~Hz}$ ) noise during train passing was well reproduced by simulation.

\section{SUMMARY AND OUTLOOK}

To predict the track superstructure vibration a simulation model was built based on a co-simulation method using CAD (computer aided design), FEM (finite element method) and MBS (multi body simulation). Two models were created separately. The Munich test track model is for providing a basic understanding of ballasted superstructure behaviour under controlled shaker excitation, but without wheel/rail contact. The calculated and the measured track natural frequencies agreed well. Based on this model, the wheel/rail contact was established on it and a modelling concept to achieve the transient co-simulation between the structural vibration and the sound radiation under the excitation of rail/wheel contact were developed.

The transient Rothenthurm track model, validated by the field measurement "Rothenthurm" is designed for the investigation of high frequency vibrations during the train running along the track with real wheel/rail contact excitation. The transient Rothenthurm track model was validated under limited conditions but met the general, measured vertical vibration accelerations up to about $2,000 \mathrm{~Hz}$. Following criteria require further investigation:

- Effects of wheel-rail contact damping and vibration;

- Effects of rail and wheel roughness;

- Effects of the non-linear behaviour of the entire superstructure system (rail and sleeper support).

\section{ACKNOWLEDGEMENT}

The authors would like to acknowledge the financial support of the Federal Office for the Environment (BAFU) Switzerland.

\section{REFERENCES}

[1] Freudenstein, S., Zhang, J. \& Mack, J., Modularer Workflow zur Modellierung der Dynamik von Oberbausystemen und dessen Validierung. ZEVrail, Ausgabe 04/2018, S. 132-137, 2018.

[2] Hecht, M., Sohr, S., Zhang, J., Lechner, B., Gwenael, H., Zemp, A. \& Wunderli, J., Entwicklung eines Simulationstools zur Auslegung lärmarmer Gleiskonstruktionen. ZEVrail, Ausgabe 10/2018, S. 400-409.

[3] Zhang, J., Lechner, B., Freudentstein, S., Sohr, S., Hecht, M., Wunderli, A., Zemp, A. \& Gwenael, H., Entwicklung eines Oberbaukörperschallmodells. Der Eisenbahn Ingenieur, Ausgabe 03/2019, S. 9-14.

[4] Zhang, J. \& Mack, J., Research Report 3493: Field Measurement at Rothenthurm (CH) for Input Data of Simulation Model and Model Validation (14th of Nov. 2016). 